\title{
Plants Used by Pregnant Women at Kipushi City in Democratic Republic of Congo: Prevalence and Indications
}

\author{
Khang Imvar Esther1, Kataka Zabadi Kleph', Kaki Khang Mariette², Yayila Nsimba Sylvie², \\ Wetshi Ongona Tchomba Andre ${ }^{1}$, Lakula Niclette ${ }^{3}$, Kabamba Nzaji Michel ${ }^{4}$, \\ Kalonji Ndumba Jean Baptiste5, Luboya Numbi Oscar6
}

\author{
${ }^{1}$ Management \& Biomedical Technology Section, Medical Biology Department, Institute of Higher Medical \\ Techniques of Lubumbashi, Lubumbashi, Democratic Republic of Congo \\ ${ }^{2}$ Nursing, Higher Institute of Medical Techniques of Lubumbashi, Lubumbashi, Democratic Republic of Congo \\ ${ }^{3}$ Management \& Biomedical Technology Section, Nutrition and Dietetics Department, Institute of Higher Medical Techniques of \\ Lubumbashi, Lubumbashi, Democratic Republic of Congo \\ ${ }^{4}$ Department of Public Health, Faculty of Medicine, University of Kamina, Kamina, Democratic Republic of Congo \\ ${ }^{5}$ Department of Galenic Pharmacy and Drug Analyzes, Faculty of Pharmaceutical Sciences, University of Lubumbashi, \\ Lubumbashi, Democratic Republic of Congo \\ ${ }^{6}$ Department of Public Health, Faculty of Medicine, Lubumbashi University, Lubumbashi, Democratic Republic of Congo \\ Email: michelnzaji@yahoo.fr
}

How to cite this paper: Esther, K.I., Kleph, K.Z., Mariette, K.K., Sylvie, Y.N., Andre, W.O.T., Niclette, L., Michel, K.N., Baptiste, K.N.J. and Oscar, L.N. (2017) Plants Used by Pregnant Women at Kipushi City in Democratic Republic of Congo: Prevalence and Indications. Open Access Library Journal, 4: e3390.

https://doi.org/10.4236/oalib.1103390

Received: January 19, 2017

Accepted: February 24, 2017

Published: February 27, 2017

Copyright $\odot 2017$ by authors and Open Access Library Inc.

This work is licensed under the Creative Commons Attribution International License (CC BY 4.0).

http://creativecommons.org/licenses/by/4.0/

\begin{abstract}
The use of plants in our immediate environment in primary health care in Africa and especially among the poor, is a very common practice. Our study aimed to determine the profile and frequency of pregnant using medicinal plants; and to identify medicinal plants most frequently used during pregnancy. We have done a descriptive cross-sectional study, conducted for up March 2014 to June 2014, on a sample of 400 pregnant women who consulted health centers of the city Kipushi during prenatal consultations. Of a total of 400 pregnant consulted during the investigation period, $30 \%$ or $7.5 \%$ used medicinal plants, $46.67 \%$ had an age between 26 and 30 years, the majority of pregnant or $56.67 \%$ had a secondary consideration; 13 pregnant using medicinal plants is $43.33 \%$ were multiparous pregnant while 10 , $33.33 \%$ were large multiparous pregnant $12 \%$ or $40 \%$ were married and $9 \%$ or $30 \%$ of pregnant were single. The Birsocorpus orientaris was the most used plants in pregnant or $16.67 \%$ of pregnant monitoring and Uapaca kirkiana, Ficus capensis or $13.33 \%$ and $10 \%$ of these used the pregnant Thespesia garckeana, Hibiscus cannabinus or Liposes. These results provide the basis for subsequent studies to experimentally evaluate the potential of these plants. This will make available for women in labor, new substances of natural origin.
\end{abstract}

\section{Subject Areas}

Plant Science 


\section{Keywords}

Medicinal Plants, Pregnant Women, Prevalence, Indication

\section{Introduction}

For centuries and even millennia, our ancestors used plants to relieve their pain, heal their ailments and heal their wounds. From generation to generation, they passed on their knowledge and simple experiments by working when they could record them in writing [1].

At the moment when humanity is facing all kinds of diseases and where the care of health issues is proving a real social problem, especially in developing countries with inadequate resources result in low economic systems. A use of readily available local resources constitutes a real workaround and that in view of the Millennium Development Goals. Despite advances in biology and medicine of the time, the majority of people in developing countries lack access to adequate health care due to low economic systems. For this reason, the plant resources figure prominently in the lives of these populations [2].

The African continent is full of very diverse medicinal plants. According to the World Health Organization, more than $80 \%$ of the African population makes use of traditional medicine and pharmacopoeia to deal with health problems. On roughly 300,000 species of medicinal plants identified on the planet, more than 200,000 live in the tropics of Africa and have medicinal properties [3].

Medicinal plants are a valuable heritage for humanity and especially for the majority of poor communities in developing countries who depend on it for their primary health care and their subsistence. They use most plant species, both woody and herbaceous, as drugs. A well-held belief is that any plant treats [4].

In all developing countries such as the Democratic Republic of Congo, medicinal plants are the most used medium especially in rural areas to address public health problems. According to the WHO in 2002, over $80 \%$ of the African population use plants for their health care needs [5].

Indeed, given the belief in the harmlessness of medicinal plants because of their natural origin, their use becomes increasingly considered a reasonable alternative and safer than conventional therapy? Since pregnant women may have to face fear teratogenicity conventional drugs, it can be assumed that medicinal plants are common therapies during pregnancy. Indeed, studies in, America and elsewhere show that up to $55 \%$ of women use medicinal plants during the gestational period [6].

Given the importance and the value we place on this study of the practice of medicinal plants in pregnant, we have set the following objectives:

- Determine the profile of pregnant using medicinal plants;

- Determine the frequency of the use of medicinal plants in pregnant;

- Identify the most frequently used herbs during pregnancy. 


\section{Material and Method}

\subsection{Study Site}

Kipushi is a southwestern area of the province of Katanga in Democratic Republic of Congo, Located near the border with Zambia $(500 \mathrm{~m})$, to the southwest of Lubumbashi, or about thirty kilometers from the latter. This area is known for its important minescopper and of zinc. KIPUSHI territory is perched at 1200 meters altitude on the top shelf Katanga. It owes its existence to what was one of the jewels of the Mining Union: Prince Leopold Mine and its famous V Wells. The population of the territory of Kipushi is estimated at 349,004 inhabitants according to the annual report 2014 of the administration of the territory.

\subsection{Study Design}

This is a descriptive cross-sectional study for up March 2014 to June, 2014. Our sample consisted of 400 pregnant women who were enrolled in the health centers of the city Kipushi during prenatal consultations. Any pregnant present at the antenatal clinic, with verbal consent to participate in the study was included. Mother does not cooperate were excluded from the study. The following information was collected: using medicinal plants by women, age in years, tribes, level of study, parity, civil status, common names of plants, parts of plants used, administration mode, plant species, Indication, processing mode.

The collected data were coded, entered, processed and analyzed using SPSS 19. Descriptive analysis was performed using the proportions calculations. Verification of tax on names was made in the laboratory of the Faculty of Science of the University of Lubumbashi.

This study was approved by related ethics committee besides and mothers sign informed consent and have a whole understanding of this study. Our study had no binding character. Any information collected from mothers has been and will remain confidential. Similarly, the names of participants will remain confidential and will not be mentioned in the presentation of results or associated to results in any way whatsoever.

\section{Results}

Table 1 shows that, of a total of 400 pregnant consulted during the investigation period, $30(7.5 \%)$ used medicinal plants.

Table 2 shows that 14 pregnant or $46.67 \%$ had an age between 26 and 30 years, followed by pregnant 9 (30\%) whose age range was between 22 and 26 years, $33.33 \%$ of these were pregnant the Bemba tribe, pregnant practicing agriculture rank first or $36.67 \%$. The majority of pregnant or $56.67 \%$ had a secondary consideration; 13 pregnant using medicinal plants is $43.33 \%$ were multiparous pregnant while $1033.33 \%$ were large multiparous pregnant $12 \%$ or $40 \%$ were married and $9 \%$ or $30 \%$ of pregnant were single.

Table 3 shows Birsocorpus orientaris were the most used plants in pregnant or $16.67 \%$ of pregnant) monitoring and Uapaca kirkiana, Ficus capensis or 
Table 1. Prevalence of use of medicinal plants by the pregnant.

\begin{tabular}{ccc}
\hline Women using medicinal plants & Effective (nor) & Percentage (\%) \\
\hline Yes & 30 & 7.5 \\
No & 370 & 92.5 \\
Total & 400 & 100 \\
\hline
\end{tabular}

Table 2. Profile of pregnant using medicinal plants.

\begin{tabular}{|c|c|c|}
\hline Age in years & Effective (nor) & Percentage (\%) \\
\hline $18-22$ & 1 & 3.33 \\
\hline $22-26$ & 9 & 30.00 \\
\hline $26-30$ & 14 & 46.67 \\
\hline $30-34$ & 6 & 20.00 \\
\hline \multicolumn{3}{|l|}{ Tribes } \\
\hline Bemba & 10 & 33.33 \\
\hline Sanga & 1 & 3.33 \\
\hline Rund & 8 & 26.67 \\
\hline Luba from Kasai & 2 & 6.67 \\
\hline Luba of Katanga & 9 & 30.00 \\
\hline \multicolumn{3}{|l|}{ Profession } \\
\hline Saleswoman & 9 & 30.00 \\
\hline Household & 6 & 20,00 \\
\hline Farmer & 11 & 36.67 \\
\hline Teachers & 2 & 6.67 \\
\hline Prostitutes & 2 & 6.67 \\
\hline \multicolumn{3}{|l|}{ Level of study } \\
\hline Primary & 11 & 36.67 \\
\hline Secondary & 17 & 56.67 \\
\hline University & 2 & 6.67 \\
\hline \multicolumn{3}{|l|}{ Parity } \\
\hline Primipare & 7 & 23.33 \\
\hline Multipare & 13 & 43.33 \\
\hline Grand multipare & 10 & 33.33 \\
\hline \multicolumn{3}{|l|}{ Civil status } \\
\hline Single & 9 & 30.00 \\
\hline Married & 12 & 40.00 \\
\hline Divorced & 6 & 20.00 \\
\hline Widow & 3 & 10.00 \\
\hline
\end{tabular}


Table 3. Distribution of medicinal plants used by the pregnant.

\begin{tabular}{cccc}
\hline Common names of plants & The scientific names of plants & $\begin{array}{c}\text { Effective } \\
\text { (nor) }\end{array}$ & $\begin{array}{c}\text { Proportion } \\
(\%)\end{array}$ \\
\hline Makole & Thespesia garckeana & 3 & 10.00 \\
Kisongole & Strychnos cocculoides & 1 & 3.33 \\
Masuku & Uapaca kirkiana & 4 & 13.33 \\
Madjere & Phyllanthus mwellerinus & 2 & 6.67 \\
Mukiluakilua & Ficus capensis & 4 & 13.33 \\
Mulenda & Hibiscus cannabinus & 3 & 10.00 \\
Kandasole & Birsocorpus orientaris & 5 & 16.67 \\
Mumono & Ricinus comninus & 2 & 6.67 \\
Aloe & Lipose & 3 & 10.00 \\
Matungulupoli & Afranomum alboviolaceum & 2 & 6.67 \\
Lukumba & Cymbopongo citratus & 1 & 3.33 \\
Total & & 30 & 100.00 \\
\hline
\end{tabular}

$13.33 \%$ and $10 \%$ of these used the pregnant Thespesia garckeana; Hibiscus cannabinus either Liposes.

Table 4 shows that $36.6 \%$ of pregnant using the roots followed in $30 \%$ of the leaves. In connection with the mode of administration of medicinal plants, $50 \%$ of pregnant were using oral and $13.3 \%$ vaginal or anal (Table 5).

\section{Discussion}

The frequency of use of medicinal plants obtained in our study was approximately $7.5 \%$. This is relatively low compared to other similar studies in subSaharan Africa; $12 \%$ in Kenya in a district hospital; 50.4\% in Ethiopia and 50.0\% in Harére [7]. The study by Tariku et al. [8] showed that 73.1\% of women had used herbal medicines during pregnancy and while Dabaghian Hashem al found a $67 \%$ of the 600 pregnant women who had used at least one of the herbal medicines during their current pregnancy or earlier [9]. But the study by Krysell shows a $9 \%$ prevalence in canada [6]. The difference may be due to the characteristics of the study population at the time of the study, the inclusion criteria, the sample size, sampling methods, the type of questions in the questionnaire and method of data collection, but also to the culture and level of study of the different populations studied.

Our study found that the roots were much used by pregnant or $36.67 \%$. Our results are not consistent with those in the literature. Indeed, studies by ethnobotanicals Zirihi (1991) 64.49\%, Tra Bi (1997) 70\% Ouattara (2006) 44.26\% Zerbo et al. (2007) 41\%, N'Guessan (2008) 51.22\% Lakouetene et al. (2009) 67\%, Zerbo et al. (2011) 31\% and Diatta et al. (2013) 46\% showed that the leaves were the parts mainly used in various therapeutic preparations [10]. One might worry about overuse leaves of medicinal plants, but studies by Poffenberger et al. 
Table 4. Distribution of medicinal plants used by the party and its mode of administration by the pregnant.

\begin{tabular}{ccc}
\hline Parts of plants used & Effective $(\mathbf{n}=\mathbf{3 0})$ & Proportion (\%) \\
\hline Roots & 11 & 36.6 \\
Leaves & 9 & 30.0 \\
Bark & 5 & 16.7 \\
Fruit & 5 & 16.7 \\
Administration mode & 15 & 50.0 \\
Oral & 7 & 23.4 \\
Bath & 4 & 13.3 \\
Vaginally & 4 & 13.3 \\
Anally & & \\
\hline
\end{tabular}

Table 5. Distribution of medicinal plants according to their kinds and ways of treatment.

\begin{tabular}{|c|c|c|}
\hline Plant species & Indication & Processing mode \\
\hline $\begin{array}{l}\text { Thespesia } \\
\text { garckeana }\end{array}$ & Membrane rupture & $\begin{array}{l}\text { Roots decoctus: Drink morning, evening drinks at } 9 \text { months of pregnancy. } \\
\text { Leaves: make a sitz bath to } 9 \text { months. }\end{array}$ \\
\hline $\begin{array}{l}\text { Strychnos } \\
\text { cocculoides }\end{array}$ & Uterine contractions, contracted pelvis & $\begin{array}{l}\text { Roots decoctus: Drink morning, evening } 2 \text { glasses. } \\
\text { pounded leaves mixed with palm oil: make the anus to } 8 \text { months pregnant. }\end{array}$ \\
\hline $\begin{array}{l}\text { Uapaca } \\
\text { kirkiana }\end{array}$ & $\begin{array}{l}\text { Uterine contractions, } \\
\text { rupture of the membrane }\end{array}$ & $\begin{array}{l}+ \text { Pounded leaves of palm oil: vaginal } 9 \text { months of pregnancy. } \\
\text { Roots decoctus: drinking. Peel: cover }\end{array}$ \\
\hline $\begin{array}{l}\text { Phyllanthis } \\
\text { mwellerinus }\end{array}$ & Uterine contractions, cervical dilation & $\begin{array}{l}\text { Roots: sitz bath for } 9 \text { months of pregnancy. } \\
\text { Leaves and dried to powder + palm oil: anally } 9 \text { months of pregnancy. }\end{array}$ \\
\hline $\begin{array}{l}\text { Ficus } \\
\text { capensis }\end{array}$ & $\begin{array}{l}\text { Stimulate uterine contractions, } \\
\text { rupture of the membrane }\end{array}$ & $\begin{array}{l}\text { Roots decoctus: Drink } 1 \text { glass morning } \\
\text { and evening to } 9 \text { months of pregnancy. }\end{array}$ \\
\hline $\begin{array}{l}\text { Hibiscus } \\
\text { cannabinus }\end{array}$ & $\begin{array}{l}\text { Dilation of the cervix, } \\
\text { rupture of the membrane }\end{array}$ & $\begin{array}{l}\text { Prepared fruit decoctus: drink morning } \\
\text { and evening to } 9 \text { months of pregnancy. }\end{array}$ \\
\hline $\begin{array}{l}\text { Birsocorpus } \\
\text { orientaris }\end{array}$ & Contracted pelvis, uterine contractions & $\begin{array}{l}\text { Roots: sitz bath for } 6 \text { to } 7 \text { months of pregnancy. } \\
\text { pounded leaves + oil: anally } 9 \text { months of pregnancy. }\end{array}$ \\
\hline $\begin{array}{l}\text { Ricinus } \\
\text { comninus }\end{array}$ & Avoid tear, rupture of the membrane & $\begin{array}{l}\text { Decoctus leaves: Drink } 1 \text { glass morning and evening. } \\
\text { Roots make the powder + palm oil: vaginally. Peel: hedge. }\end{array}$ \\
\hline Liposo & Avoid tearing, stimulate contractions & $\begin{array}{l}\text { Peel: to powder + palm oil. Roots decoctus: Drink morning. } \\
\text { Sheets prepared: drink morning and evening to } 9 \text { months of pregnancy. }\end{array}$ \\
\hline $\begin{array}{l}\text { Afranomum } \\
\text { alboviolaceum }\end{array}$ & Stimulate uterine contractions & $\begin{array}{l}\text { Roots: to put the powder in the anal. decoctus Sheets: } \\
\text { drink morning and evening to } 9 \text { months of pregnancy. }\end{array}$ \\
\hline $\begin{array}{l}\text { Cymbopongo } \\
\text { citratus }\end{array}$ & $\begin{array}{l}\text { Rupture of the membrane, } \\
\text { contracted pelvis, neck opening }\end{array}$ & $\begin{array}{l}\text { Roots decoctus: drink morning and evening. } \\
\text { Leaves: powder + palm oil. Peel: hedge. }\end{array}$ \\
\hline
\end{tabular}

showed that the removal of $50 \%$ of the leaves of a tree does not significantly affect its survival. Also, the high frequency of use of sheets can be explained by the ease and speed of harvesting but also by the fact that they are the site of photosynthesis and storage of secondary metabolites responsible for the biological properties of the plant [11]. But note that the study undertaken by Bene Kouadio has shown that the roots, with $10 \%$ of cases were the second group of the most used organs after the leaves [10]. 
Among the administration routes, the most used was oral in $50 \%$ of cases. N'Guessan and Dibong et al. also found that $94.44 \%$ of respondents have used the oral route [12]. Nevertheless, several studies reveal other ways [10]. The difference found in modes of administration would be due to the different people's cultures. With us, the majority of preparation for medicinal plants are potions, since these are the most simple and easy to achieve.

The predominance of 3 families (Birsocorpus orientaris, Uapaca kirkiana, Ficus capensis) which have the largest number of medicinal plants traditionally used for their likely effects oxytocin, is explained by the fact that these families are members, from the perspective of the number of species they contain, the largest of the flora of the city of Kipushi. We note with Ouattara, $031.78 \%$ representing plants of plants directory identified during ethno pharmacological study conducted in the region of Divo. Tra Bi showed that 08 plant species (8.88\%) constituted the bulk of the arsenal of taxa used to ease childbirth. Zirihi (1991) reported that the Bete Department Issia (Central West of Ivory Coast) employ 05 plants, or $4.31 \%$ of all known plants. Vangah (1986) indicates that the Akan ethnic groups in the coastal region of the Ivory Coast use 24 species of plants engaged in oxytocin effects; these plants represent $7.97 \%$ of all known plants. Adjanohoun and Aké Assi (1979) has reported 5 species of plants, or $1.65 \%$ of the repertoire of taxa identified during their study on medicinal plants of Ivory Coast. This variability is due to changes in the methods of investigation; it could be explained by differences in region and vegetation.

\section{Conclusions}

Medication by plants is an ancient therapy and millennium. It goes back to the dawn of time. Mankind has always sought to use plants to survive and to draw remedies to relieve his pain. This work was conducted in order to determine the profile of pregnant using medicinal plants, the frequency of the use of medicinal plants in pregnant and to identify the most commonly used herbs during pregnancy.

The results showed $7.5 \%$ of pregnant using medicinal plants. The Birsocorpus orientaris was the most used plants in pregnant or $16.67 \%$ of pregnant) monitoring and Uapaca kirkiana, Ficus capensis or $13.33 \%$ and $10 \%$ of these used the pregnant Thespesia garckeana; Hibiscus cannabinus either Liposes.

The use of more sophisticated methods of screening phytochemical and evaluation of the pharmacological activity of various extracts would be important to complete this ethnobotanical study.

\section{References}

[1] Ouafae, B., Lahcen, Z., Mohamed, F. and Houda, E. (2011) Ethnobotanical Study of Medicinal Plants in the Region of Bel Mechraâ Ksiri (Gharb Region of Morocco). Acta Botanica Barcinonensia, 53, 191-216.

[2] Mokoso, M., God, J., De Felicien, M.K. and Justin, K.N. (2014) Contribution to the Phytochemical Study of Some Medicinal Plants Antidiabetic from the Town of Bukavu and Its Environs (South Kivu, RD Congo). Journal of Applied Biosciences, 75, 
6211-6220.

[3] Loubna, E. (2015) Ethnobotanical Survey of Antidiabetic Plants with Herbalists in the City of Fez. Sidi Mohamed Ben Abdellah University, Fez.

[4] Salhi, S., Fadli, M., Zidane, L. and Douira, A. (2010) Floristic and Ethnobotanical Studies of Medicinal Plants in the City of Kenitra (Morocco). Lazaroa, 31, 133-146. https://doi.org/10.5209/rev_LAZA.2010.v31.9

[5] Dro, B., Soro, D., Koné, M.W., Bakayoko, A. and Kamanzi, K. (2013) Evaluation of the Abundance of Medicinal Plants Used in Traditional Medicine in Northern Côte d'Ivoire. Journal of Animal \& Plant Science, 17, 2631-2646.

[6] Moussally, K. (2009) The Use of Medicinal Plants: Prevalence, Determinants and Risk of Prematurity. Montreal University, Montreal.

[7] Vanotoo, L., Detoh, E.K., Oduro, J. and Nsiah, R.B. (2015) Utilized Type of Herbal Medicines by Pregnant Women Attending Ante-Natal Clinic in Offinso North District: Orthodox Prescribers Are Aware? Ghana Medical Journal, 49, 227-232.

[8] Laelago, T., Yohannes T. and Lemango, F. (2016) Prevalence of Herbal Medicine Use and Associated Factoring among Pregnant Women Attending Prenatal Care at Public Health Facilities in Hossana Town, Southern Ethiopia: Facility Based Cross Sectional Study. Archives of Public Health, 74, 7.

https://doi.org/10.1186/s13690-016-0118-z

[9] Hashem Dabaghian, F., Abdollahi Fard, M., Shojaei, A., Kianbakht, S.N. and Zafarghandi, G.A. (2012) Use and Attitude on Herbal Medicine in a Group of Pregnant Women in Tehran. Journal of Medicinal Plants, 11, 22-33.

[10] Kouadio, B., Djeneb, C., N’Guessan, F.N., Yvette, B. and Christmas, Z.G. (2016) Ethnobotanical Study of Medicinal Plants Used in the Department of Transua, District Zanzan (Ivory Coast). Journal of Animal \& Plant Sciences, 27, 4230-4250.

[11] N'Guessan, F.H. and Tra Bi, W.K. (2009) Ethnopharmacological Study of Antimalarial Plants Used in Traditional Medicine among Abbey and Krobou of Agboville (Ivory Coast). Ethnopharmacologia, 22, 42-50.

[12] N'Guessan, K.N., Guede, N., Kama, N.T. and Boraud, M. (2010) Study Ethnopharmacological Plants Used to Facilitate Childbirth, Countries and Krobou Abbey, South of Côte d'Ivoire. International Journal of Biological and Chemical Sciences, 4 , 1004-1016.

Submit or recommend next manuscript to OALib Journal and we will provide best service for you:

- Publication frequency: Monthly

- 9 subject areas of science, technology and medicine

- Fair and rigorous peer-review system

- Fast publication process

- Article promotion in various social networking sites (LinkedIn, Facebook, Twitter, etc.)

- Maximum dissemination of your research work

Submit Your Paper Online: Click Here to Submit

Or Contact service@oalib.com 